\title{
UM REGIME DE TRANSIÇÃO: O PAPEL DO IHGSP NO CURSO DE HISTÓRIA DA UNIVERSIDADE DE SÃO PAULO (1934)
}

A transition regime: the role of the IHGSP in the History course of the University of Sáo Paulo (1934)

Un régimen de transición: el papel del IHGSP en el curso de historia de la Universidad de São Paulo (1934)

ARYANA COSTA $I^{*}$

DOI: : http://dx.doi.org/10.1590/\$2178-14942019000200010

\footnotetext{
'Universidade do Estado do Rio Grande do Norte (Uern), Mossoró, Brasil.

* Departamento de História da Universidade do Estado do Rio Grande do Norte (Departamento de História/FAFIC/UERN), Mossoró, Brasil. (aryanacosta@gmail.com). OCID iD: http://orcid.org/0000-0003-0208-778X
}

Artigo recebido em 23 de janeiro de 2019 e aprovado em 5 de julho de 2019. 


\title{
RESUMO
}

Este artigo busca compreender, por meio das atas da revista do IHGSP, o interesse de membros desse instituto na composição do quadro docente e nos debates sobre saberes e currículos do curso de geografia e história, inaugurado em 1934 na USP. Nesse intuito, usamos o caso de Plinio Ayrosa para identificar as práticas que esses novos professores levaram consigo para a universidade. Assim, foi possível problematizar uma memória institucional já estabelecida que apaga esses sujeitos da história do curso e que, consequentemente, limita sua dimensão na história da historiografia brasileira.

PALAVRAS-CHAVE: IHGSP; USP; História da historiografia; Curso de história; Plinio Ayrosa.

\begin{abstract}
This article studies, through the records of the IHGSP Journal, the engagement of this Institute's members in the configuration of the faculty of the Geography and History course installed in USP in 1934, and in the debates over its contents and curricula. The case of Plinio Ayrosa was useful in identifying the practices these new professors were bringing to the university. It was thus possible to reopen the discussion on an already established institutional memory which erases these figures from the history of the course and, as a consequence, diminishes their participation in the history of Brazilian historiography.
\end{abstract}

KEYWORDS: IHGSP; USP; History of historiography; History course; Plinio Ayrosa.

\section{RESUMEN}

Este artículo busca comprender el interés de miembros del IHGSP en la composición del cuadro docente y en los debates sobre saberes y currículos del curso de geografía e historia, inaugurado en 1934 en la USP, a través de las actas de la revista del instituto. En ese sentido, usamos el caso de Plinio Ayrosa para identificar las prácticas que esos nuevos profesores llevaron consigo a la universidad. Así, fue posible problematizar una memoria institucional ya establecida que apaga a esos sujetos de la historia del curso y que, consecuentemente, limita su dimensión en la historia de la historiografía brasileña.

PALAbRAS ClaVE: IHGSP; USP; Historia de la historiografía; Curso de historia; Plinio Ayrosa. 


\section{INTRODUÇÃO}

$\mathrm{O}$ curso de geografia e história na Universidade de São Paulo (USP) foi criado em 1934. Em entrevistas, as memórias de seus docentes e ex-alunos sobre sua fundação e seu funcionamento constroem uma clivagem entre dois grupos de professores, divididos entre inovadores e tradicionais, no que se refere aos diferentes entendimentos acerca de teoria e metodologia da história e também da metodologia de sala de aula. Por um lado, ressaltam a inovação trazida pela experiência e pela produção dos professores franceses Fernand Braudel e Jean Gagé, os primeiros a ocuparem a cátedra de história geral da civilização. Por outro lado, atribuem os rótulos de "conservadores" e "tradicionais" ao trabalho dos professores brasileiros que ocuparam as cátedras de história da civilização brasileira e etnografia brasileira - Afonso Taunay e Alfredo Ellis Junior -, bem como língua tupi-guarani, Plinio Ayrosa.

As narrativas de origem do curso remetem em especial ao lugar ocupado pelos professores franceses e sua posição de centralidade e importância na consolidação do saber histórico e geográfico, ao passo que oblitera a participação dos professores brasileiros e de suas questões e interesses no processo de disciplinarização desses saberes. Motivados por essa separação, a proposta deste artigo é compreender a fundação do curso de geografia e história na USP, por meio de debates e articulações ocorridas no âmbito do Instituto Histórico e Geográfico de São Paulo (IHGSP), instituição a que pertenciam os professores brasileiros do curso, como um dos lugares precípuos do debate sobre história e geografia no Brasil.

Assim, este artigo se volta para a etapa anterior ao início do curso apresentado pelos Anuários da Faculdade de Filosofia, Ciências e Letras ( $F F C L$ ), para aquela que corresponde à concepção e à organização dos saberes numa configuração curricular. Enfoca especialmente o debate em torno da disciplina de etnografia brasileira e língua tupi-guarani, presente nos três anos da grade curricular, o que denota sua relevância. Nas atas da Revista do Instituto Histórico Geográfico de São Paulo (RIHGSP), encontram-se debates e articulações ocorridos no primeiro semestre de 1934 entre membros dessa instituição e as autoridades governamentais paulistas para a implantação desse curso.

Por meio da análise dessas atas, é possível construir outra narrativa desse início que complementa aquelas que já conhecemos e que pertence também a essa história, mesmo que referente a um período imediatamente anterior ao início das aulas. Neste artigo, é proposto que as décadas de 1930 e 1940, quando a primeira geração formada pela universidade ainda se encontrava num processo de convivência entre os regimes de produção historiográfica nacional e estrangeira já existentes, foram igualmente um período de convivência entre diferentes entendimentos sobre a atuação de um profissional de história. 


\section{O IHGSP DENTRO DE CADA UM}

$\mathrm{O}$ IHGSP foi fundado em 1894, e sua organização e seus propósitos eram muito parecidos com os do Instituto Histórico e Geográfico Brasileiro (IHGB). Em 1932, a admissão de sócios se fazia por indicação - era necessária uma proposta assinada por três ou mais sócios efetivos, que deveria conter os dados pessoais do candidato e seus méritos. Era obrigatória também a apresentação de "um trabalho científico" sobre assunto de história ou geografia "precipuamente" de São Paulo (RIHGSP, 1933-1934: 469-469). Esse conjunto seria apreciado pela comissão de admissão de sócios e pela comissão técnica respectiva - caso fosse um trabalho de história do Brasil, de São Paulo, de geografia ou de etnografia -, que emitiriam pareceres a serem aprovados em assembleia.

No período aqui retratado - o início da década de 1930 -, o IHGSP vinha sofrendo com deficiências orçamentárias, por ter deixado de receber as subvenções do governo do estado pelos anos consecutivos de 1929, 1930 e 1931. 0 volume 29 de sua revista, referente a 1931, por exemplo, não pôde ser publicado por falta de verba. Em 1932, ano conturbado por causa da Revolução Constitucionalista, o instituto contava com 156 sócios (RIHGSP, 1931-1932: 118). Em 1934, porém, já somava 206 sócios, e, em 1935, 222. A turbulência dos três primeiros anos da década de 1930 parece ter se arrefecido a partir de 1933, mas os relatórios não deixam de ter um tom negativo. Não obstante a procura por filiações aumentasse, o que denota uma constância no interesse pelo instituto, os volumes de sua revista continuavam saindo com atraso - o de número 30 não saíra no prazo -, e ainda não havia instalações adequadas para seu museu e seu arquivo.

Apesar da resolução do estatuto de 1932 de não envolvimento em questões políticas (RIHGSP, 1933-1934: 481), os membros não deixavam de lançar mão de seus estreitos contatos com o poder público para tentar resolver a situação financeira. Em 1936 e 1937, parcerias e convênios com a prefeitura e o governo do estado foram estabelecidos para que o instituto exercesse atividades de restauração e publicação de documentos e para conseguir uma nova sede. Em nome da história de São Paulo, o IHGSP compunha comissões e promovia celebrações para comemorações de datas, como as relativas ao quarto centenário da fundação de São Vicente.

Pouco citados nas memórias de alunos e professores, Afonso Taunay, Plinio Ayrosa e Alfredo Ellis Junior, os três professores brasileiros que compuseram o quadro docente no início do curso de história e geografia da USP, foram sócios desse IHGSP. Como já dito, Taunay e Ellis Junior ocuparam a cadeira de história da civilização brasileira, e Ayrosa, a de etnografia brasileira e tupi-guarani. Todavia, recorre-se pouco a essas figuras na construção da memória do curso e da universidade. ${ }^{1}$ 
O silêncio em relação a esses sujeitos é tributário do anacronismo com que nós, historiadores, por vezes tratamos a história da profissão. Os olhos de hoje buscam as origens daquilo que é reconhecido como legítima prática acadêmica atual, "demarcando o seu terreno em relação aos estudos empreendidos anteriormente, como os do IHGSP, tidos como 'pré-científicos', dos quais era preciso distanciar-se para sua afirmação institucional" (Ferreira, 2002: 174). Isso, somado à centralidade que a historiografia francesa adquiriu na produção historiográfica brasileira, reforça o desinteresse em relação àqueles que ainda circulavam e encontravam seu prestígio em outras redes, que inclusive gestaram e deram forma ao currículo de história na USP de 1934, como veremos.

Nascido em 1876, em Santa Catarina, Afonso Taunay teve sua formação escolar no Rio de Janeiro. Era filho do Visconde de Taunay, que também havia se enveredado pelas letras, e de Cristina Teixeira Leite Taunay. Formou-se em engenharia civil pela Escola Politécnica do Rio de Janeiro, em 1900. Trabalhou na Politécnica de São Paulo. Seu casamento com Sara de Souza Queiroz, de uma tradicional família paulistana, abriu caminhos nos círculos ilustres do estado. Em 1911, foi eleito sócio do IHGB; em 1917, nomeado diretor do Museu Paulista, e, em 1929, para a Academia Brasileira de Letras. Assumiu a cadeira de história da civilização Brasileira na USP entre 1935 e 1937, quando, por uma legislação federal, precisou se descompatibilizar de um de seus cargos. Escolheu ficar no Museu Paulista. ${ }^{2}$ Seus livros de história versam sobretudo sobre a história de São Paulo, sendo referenciado frequentemente como 0 "historiador das bandeiras".

Alfredo Ellis Junior nasceu em São Paulo, em 1896. ${ }^{3}$ Foi aluno de Taunay no Colégio São Bento e se formou pela Faculdade de Direito, em 1917, seguindo a carreira de promotor público (Monteiro, 1994: 80). Escreveu para o jornal Correio Paulistano e também para o Jornal do Commercio, cujos artigos deram origem aos seus dois primeiros livros: 0 bandeirismo paulista e o recuo do meridiano (1924) e Raça de gigantes (1926). Ellis participou da Liga de Defesa Paulista por ocasião da guerra de 1932; escreveu livros didáticos nas áreas de história, geografia, estatística, biologia e higiene; e deu aulas em ginásios da capital. Antes de entrar para a universidade, Raça de gigantes foi reeditada com o título Os primeiros troncos paulistas, pela Companhia Editora Nacional. Substituiu Taunay na cadeira de história da civilização brasileira, em 1938, tornando-se catedrático em 1939, ao defender a tese Meio Século de bandeirantismo, também publicada pela Editora Nacional.

Plinio Marques da Silva Ayrosa nasceu em São Paulo, em 1893. Estudou na Escola Politécnica do Rio de Janeiro, formando-se engenheiro civil em 1920, com uma especialização em Berlim. Escreveu para vários jornais até entrar, em 1934, para os quadros da nova Faculdade 
de Filosofia, Ciências e Letras. Antes disso, já havia publicado Primeiras noções de tupi, em 1933, e organizado e prefaciado o Dicionário português-brasiliano e brasiliano-português, em 1934. Tornou-se catedrático da cadeira de etnografia e língua tupi-guarani em 1939, com a tese Dos índices de relação determinativa de posse no tupi-guarani. Também foi membro da Academia Paulista de Letras (1940) e de vários outros institutos históricos do país - da Bahia, de Pernambuco, do Rio de Grande do Norte, do Rio Grande do Sul e de Sergipe. Fez parte da comissão de redação da Revista de História quando esta foi fundada, em 1950. Faleceu em junho de 1961. ${ }^{4}$ Os três já faziam parte do IHGSP no momento da fundação do curso de história e geografia. Taunay, o mais velho, tomou posse em 1912. Ellis Junior, em 1927, e Ayrosa, em 1928. 0 pertencimento à mesma associação propiciou o convívio e o engajamento comum em solenidades e comissões, o que provavelmente lhes permitiu inclusive carregar essa identidade coletiva para a própria faculdade. Antes de pertencerem à USP, eram pesquisadores não só no sentido cronológico, mas no simbólico - o título de professor na universidade era mais um no rol da experiência que já traziam.

A carreira desses sujeitos seguiu, pois, a lógica inversa de prestígio acadêmico dos tempos atuais: o reconhecimento como estudiosos veio antes da atividade como professores. Circulavam num ambiente em que uma identidade paulista já vinha sendo construída no seio das letras históricas (Ferreira, 2002: 22) e que implicava uma série de atividades comuns exercidas no IHGSP, as quais serviam como definidoras de sua identidade historiadora.

Por exemplo, para Taunay, em seu discurso de posse, "entre os mais elevados títulos de associação científica de que nos devemos orgulhar no Brasil, figuram certamente os diplomas do Instituto Histórico e Geográfico de São Paulo, em magno destaque" (1914: 89). Nesse mesmo breve discurso, ele se dedica a traçar um paralelo entre o espírito dos primeiros paulistas e aquele do instituto, ambos imbuídos da missão de construir uma história nacional. Do mesmo modo que os bandeirantes foram os responsáveis pelo feito de moldar o país, a mais nobre tarefa a que o instituto podia se preocupar era "com as questões nacionais, dedicando aos assuntos brasileiros tanta atenção quanto aos regionais. É que o inspira a tradição: assim também nunca São Paulo coube dentro das suas fronteiras" (1914: 89. Grifo nosso).

O IHGSP incorporava ele mesmo o prolongamento da raça de gigantes, tarefa que não era pequena. Cabia-Ihe continuar, por meio da história de São Paulo, a história nacional. ${ }^{5}$

No mesmo ano da posse de Taunay, em outubro de 1912, também tomava posse no IHGSP George Dumas. Figura presente no cenário intelectual brasileiro desde a primeira década do século XX, Dumas teve participação importantíssima no posterior recrutamento de professores para a USP em $1934^{6}$ junto a Theodoro Fernandes Sampaio. Era Júlio de Mesquita 
Filho - proprietário do jornal O Estado de São Paulo e que tomou posse no IHGSP no fim de 1933 - quem iria primeiramente para a Europa prospectar professores para a recém-criada USP (Petitjean, 1996: 263). Mas, não podendo ir, fez a ligação entre Theodoro Sampaio e Dumas (Ferreira, 2005: 230).

Segundo Dumas, numa carta a Jean Marx, diretor do Services d'Oeuvres Françaises à I'Étranger (Sofe), "ele (Theodoro) conhece poucas pessoas ou não conhece ninguém, e se nós queremos ganhá-lo a todo custo, trazê-lo para a nossa influência, é indispensável cercá-lo em Paris de pessoas que ele admira e colocá-lo em contato direto com eles" (Idem: 266).

É Theodoro Sampaio, membro fundador do IHGSP, em que pronunciou discursos, necrológios e fez parte da comissão de etnografia - no mesmo período em que Taunay transitava pelas comissões de história de São Paulo ou de história do Brasil -, professor da Escola Politécnica, geógrafo, estudioso da língua tupi-guarani e nomeado o primeiro diretor da FFCL, quem vai à França e à Itália no primeiro semestre de 1934 para articular a contratação dos professores estrangeiros que deveriam ocupar as cátedras recém-criadas na FFCL.

Vê-se que as pessoas que farão parte do curso de história e geografia circulam pelo mesmo espaço já ao menos nas duas décadas que antecedem o decreto de criação da USP, compartilhando ali um ethos acerca do exercício do historiador, um conjunto de interesses e, igualmente importante, uma rede de sociabilidades. Tanto que algumas das atividades promovidas e praticadas pelo instituto ao longo dos anos 1920 e no início dos anos 1930 ganharão continuidade na estrutura do curso, em especial aquelas que tratam dos estudos indígenas, assunto de grande interesse dos seus membros.

\section{UMA NOVA FUNÇÃO: PROFESSOR}

área de etnografia e de língua tupi-guarani é um dos elementos de continuidade
entre a "velha" e a "nova" instituição. Há uma identificação criada entre o IHGSP e a responsabilidade pela manutenção dos estudos e da existência da língua tupi-guarani. Em 1925, Spencer Vampré, professor da Faculdade de Direito que viria a ser incorporada à USP, já sugeria ao instituto a criação de um curso para seu estudo. Em 1933, cria-se um no Centro do Professorado Paulista. Dessa vez o curso é regido por Plinio Ayrosa, já sócio do instituto à época, e recebe um voto de louvor do IHGSP pelo "interesse demonstrado na cultura da língua tupi e, também, pela circunstância de se valer para isso, dos conhecimentos do nosso distinto primeiro secretário" (RIHGSP, 1933-1934: 391). Plinio Ayrosa, futuro professor da USP, permite vislumbrar como esse investimento do IHGSP refletiu na configuração do curso de geografia e história, e é essa conexão que será exemplificada neste tópico.A posse de Ayrosa como 
professor catedrático da USP é tida como o reconhecimento da missão original do instituto. Plinio de Barros Monteiro explora essa identificação no discurso de homenagem a Plinio Ayrosa quando este é aprovado como catedrático na cadeira de etnografia brasileira e tupi-guarani. É assim que se descobre que a própria existência da cadeira no curso da FFCL é obra do IHGSP:

Além disso, Srs. consócios, cumpre-me fazer-vos cientes de uma coincidência de alta relevância para este Instituto, no concernente à criação da cadeira de Etnografia Brasileira. Ao iniciar-se a vida desta instituição, o seu primeiro presidente lançava um apelo aos sócios para que se dedicassem ao estudo do tupi-guarani; e, quarenta e quatro anos mais tarde, revivendo essa mesma ideia, porém querendo dar-Ihe feição mais prática, empenhou-se o nosso atual presidente perpétuo, Sr. Dr. Torres de Oliveira, junto ao então interventor deste Estado, o Sr. Armando de Sales Oliveira, para que, entre as matérias professadas na Faculdade de Filosofia, figurasse a língua tupi-guarani. A vitória que tão honrosamente coube a um destacado sócio deste cenáculo, no concurso que acaba de realizar-se, é motivo de júbilo para este Instituto, que tanto trabalhou para que o cultivo da língua tupi-guarani se tornasse uma realidade. (RIHGSP, 1939: 186-187. Grifo nosso) ${ }^{7}$

Desde sua posse, em 1928, Ayrosa parece ter uma presença bastante querida no IHGSP. Em fevereiro daquele ano, seu nome é aprovado para integrar o quadro de sócios do instituto. Em agosto, toma posse. Naquele momento, o presidente do instituto, José Torres de Oliveira, revela que Ayrosa não era um estranho:

O Sr. presidente, dando posse ao membro recipiendário do sodalício, diz não ser. S. S. um desconhecido nesta casa de trabalho que é o Instituto Histórico e Geográfico de São Paulo, onde houve sempre quem o acompanhasse com carinho no seu curso brilhante de Engenharia na Escola do Rio de Janeiro, colimado na obtenção do prêmio de viagem à Europa, e também na sua vida jornalística. (RIHGSP, 1938: 309).

Ayrosa teria vida bastante ativa no instituto. Entre suas atividades estavam a participação nas comissões de trabalho - dividiu-se entre a comissão de redação da revista e a de etnografia - e na organização dos festejos comemorativos para o Quarto Centenário da Fundação de São Vicente, com Taunay e Alberto Penteado; a organização da biblioteca do Instituto em 1929; a indicação para primeiro secretário - e diretor da biblioteca e mapoteca do Instituto - em 1932; e, em 1933, a leitura de vários estudos ao final das sessões sobre termos de origem tupi no vocabulário brasileiro. Em suas próprias palavras, ficamos sabendo que Ayrosa era um "burro de carga." Ele assim relata seu envolvimento, em especial em 1932, nas atividades do Instituto: ${ }^{8}$ 
Imagine V. que andei trepado em escadas vertiginosas pregando bandeiras e retratos pelas paredes do nosso salão nobre depois de ter escrito mil e uma notícias para os jornais fazendo a "propaganda" dos "pândegos". Durante o dia todo numa luta com convites, com arrumações de salas, com telefonadas. [...] Logo após, secretariando a sessão com ares soberbos de historiador, quando não tinha de me postar junto à máquina de projeção para pôr na tela os documentos dos conferencistas. Cada vez mais me convenço de que sou positivamente um "bicho", um sabe-tudo, um esplêndido "burro de carga". Na hora do aperto ninguém sabe fazer nada. O Ayrosa convida, o Ayrosa escreve notícias, o Ayrosa substitui fusíveis queimados, o Ayrosa recebe as personalidades mais ou menos "atenentadas", o Ayrosa fala, o Ayrosa projeta diapositivos e, por fim, o Ayrosa fecha o Instituto lá pelas 24 horas... Enfim, cada um desembaraça a meada do destino como pode (Guimarães, 1982: 8. Grifo nosso)

Em junho de 1934 - portanto, já com a USP decretada e Theodoro Sampaio em missão para garimpar professores estrangeiros -, José Torres de Oliveira comunica, para regozijo do instituto, a "notícia, ainda não confirmada, da nomeação do primeiro secretário, dr. Plinio Ayrosa, para reger a cadeira de tupi-guarani, recentemente criada na Universidade de São Paulo" (RIHGSP, 1940: 231). Em outubro, a notícia é confirmada:

O sr. presidente declara que está confirmada a notícia, em tempo levada ao conhecimento do Instituto, da provisão do consócio dr. Plinio Airosa na cadeira de tupi-guarani da Universidade de S. Paulo. Adiantou o dr. José Torres de Oliveira que o ato do governo paulista foi recebido com gerais aplausos e que ele, pensando interpretar o sentimento dos confrades do Instituto, havia endereçado ao sr. dr. Marcio Pereira Munhoz, interventor federal interino, um telegrama nos seguintes termos: "O Instituto Histórico e Geográfico de S. Paulo, cheio de júbilo pela provimento do seu digno primeiro secretário, dr. Plinio Airosa, na cadeira de tupi-guarani, criada pela clarividência do dr. Armando de Sales Oliveira na Universidade de S. Paulo, apresenta a v. exa. calorosas felicitações por esse ato acertado, com que são tão justamente aquilatados a atividade patriótica, o talento e a cultura geral e especializada do ilustre paulista, nosso prezado consócio. Deus guarde a v. exa." [...] Falou, ainda, o sócio efetivo dr. Plinio Airosa, para agradecer ao Instituto o interesse tomado pela criação da referida cadeira e também a maneira como havia recebido a notícia da sua nomeação para regê-la. Declarou que a sua maior alegria não provinha tanto do fato de ser escolhido para professor de uma matéria, que constituíra a preocupação de tantos espíritos de escol em nossa terra mas principalmente, da sua criação pelo governo, satisfazendo assim uma velha aspiração do grande Visconde de Porto Seguro, Francisco Adolfo de Varnhagen. (1940: 248. Grifo nosso)

A nomeação de Ayrosa é uma conquista do instituto, de suas relações pessoais e de um projeto político de história que buscava afirmar o papel de São Paulo na construção de uma história nacional, para o que a área dos estudos etnográficos era fundamental, pois, para estudar São Paulo, era preciso estudar seus antecedentes, "a raça de gigantes." Tendo sido a cadeira de etnografia e tupi-guarani articulada pelo seu presidente, a nomeação de um consócio era 
mais do que esperada. Ayrosa era, então, o nome dos estudos em tupi-guarani da instituição, conhecido de Armando Sales de Oliveira, e sobretudo no ano precedente ao da criação da USP figura recorrente nas atas das sessões. A definição para essa cadeira é anterior à de Taunay, sócio mais antigo e que veio a ocupar a cadeira de história da civilização brasileira.

Na correspondência trocada com seu amigo Archimedes, vê-se a confirmação do significado político que teve a campanha pela instituição dos estudos da língua tupi:

Meu bom Archimedes.

Recebi, satisfeitíssimo, as suas felicitações por motivo da minha indicação para servir como professor de tupi. Satisfeitíssimo, não propriamente por ter sido eu o escolhido, mas, por ter sido alguém, o que significa a vitória da campanha. [...] Com o início regular do curso, em março próximo, veremos quais são as disposições da nossa gente a respeito dessa inovação realmente sensacional...

Um jornal paraguaio disse há pouco que "don Plinio Ayrosa quedará en la história de la lengua guarani como él primeiro professor que tuve el mondo", oficialmente, etc., etc. Essa glória de ser o número 1, para nós colecionadores de Revistas e de Caretas, acho altamente sedutora!

(Guimarães, 1982: 15)

A coincidência levantada por Plinio Monteiro em seu discurso em homenagem à posse de Ayrosa como catedrático - de haver sido criada uma cadeira para os estudos sobre tupi serve para inscrever a experiência do curso de história e geografia como uma extensão dos esforços do instituto, o que faz, aliás, com que não seja só uma coincidência. É o instituto espraiando seu saber-fazer pelas novas instituições que surgiam. A expectativa na formação desse futuro profissional no curso da FFCL é condizente com a preocupação do IHGSP em demarcar uma identidade regional (Ferreira, 2002: 130). As ações do IHGSP incluíam um esforço para estimular as pesquisas sobre etnografia e etnologia indígenas (Idem: 138), que teriam a função de buscar os elementos indígenas que constituíram uma história paulista, composta pela ação civilizatória portuguesa e pelas qualidades guerreiras das populações nativas. $^{9}$

As palavras do próprio Ayrosa são um bom indicativo de como via esse conjunto de circunstâncias. Sem perder de vista a (falsa) modéstia que às vezes aparece nos discursos proferidos, ele, em público, comemora a conquista não pela sua indicação, mas pela criação da cadeira, ato político que classifica como extensão das aspirações de Varnhagen, aparentemente levado a cabo pelo presidente do instituto junto a Armando Sales de Oliveira. ${ }^{10}$

A modéstia com que agradece as congratulações é deixada de lado, no entanto, na sua correspondência pessoal. Ayrosa repete junto a Archimedes seu contentamento com o resul- 
tado da campanha - "satisfeitíssimo não propriamente por ter sido eu o escolhido, mas por ter sido alguém, o que significa a vitória da campanha" - e se permite deliciar-se na glória de ser o "primeiro professor de língua tupi do mundo".

A criação dessa cadeira na universidade é indicativo de quanto, desde o discurso inaugural de seu primeiro presidente, o instituto "estava certo" em insistir na salvaguarda dos estudos em língua tupi. Sua ocupação é feita por um indivíduo a quem o IHGSP vinha acompanhando mesmo antes de entrar como sócio - "não ser S. S. um desconhecido nesta casa de trabalho que é o Instituto Histórico e Geográfico de São Paulo" - e que, uma vez lá dentro, desempenhou mais de uma função, ou seja, a quem o instituto poderia dizer, de fato, que era um de seus filhos.

Essa era uma via de mão dupla. Tanto o instituto podia reivindicar Ayrosa quanto este reivindicava o instituto. Seu currículo publicado no Anuário da FFCL de 1934-1935 mostra que seu vínculo de maior expressividade são as academias a que pertence. Entre elas, o maior cargo é o de secretário-geral ocupado no IHGSP:

Bacharel em letras pelo antigo Ginásio Ciências e Letras e graduado em engenharia pela Escola Politécnica do Rio de Janeiro.

Obteve o primeiro prêmio de literatura, instituído pelo Jornal do Brasil em 1917 e direito ao prêmio de viagem à Europa para aperfeiçoamento de estudos. Encarregado de um Curso de Tupi no Centro do Professorado Paulista. Secretário Geral do Instituto Histórico e Geográfico de São Paulo e membro dos Institutos Históricos do Rio Grande do Norte, Baía e Santa Catarina.

Membro titular da Société des Americanistes de Paris, da Société de Linguistique de Paris e da Academia Paulista de Letras. (Anuário 1934-1935: 329)

Quando entra para o quadro de professores da recém-criada FFCL, Ayrosa carrega consigo, como marca maior, sua identidade como pesquisador da língua tupi chancelada pelo seu pertencimento ao Instituto Histórico e Geográfico. É essa lógica de produção que se verá presente nas suas proposições para a cadeira.

Aqui talvez valha a pena retomar ainda a questão das redes de sociabilidades. Como já visto, Theodoro Sampaio foi o elemento de ligação entre São Paulo, Itália e França para a montagem do quadro docente da universidade. Quando morre, em 1937, o IHGSP decide promover homenagens ao seu sócio fundador, escolhendo como um de seus oradores justamente Plinio Ayrosa. 0 texto depois publicado rende reflexões de duas ordens - uma que reforça 0 argumento sobre as relações pessoais como regime de legitimação para produção historiográfica do período, e a criação da USP como sua extensão, e outra que dá a ver a ideia de historiador que Ayrosa tinha. 
A fama de Sampaio vem de seus trabalhos como engenheiro, mas também de seu interesse pelos estudos em história, geografia e em língua tupi-guarani. 0 nível da proximidade entre os dois (Sampaio e Ayrosa), porém, é o que aqui nos interessa. A figura que definiu os professores estrangeiros que viriam para São Paulo foi de uma grande proximidade com Ayrosa, que chama Sampaio de grande amigo (RIHGSP, 1937, p. 273) e de saudoso mestre (Idem: 276). Perto da morte de Sampaio, Ayrosa o levou para passear em São Paulo, e um dos lugares a que o acompanhou foi a FFCL. "Levei-o à Faculdade de Filosofia e tentei levá-lo à presença do Dr. Armando Sales de Oliveira, a quem, pouco antes, elogiara entusiasticamente pela criação da cadeira de tupi-guarani em nossa Universidade" (Idem: 277).

Sendo seu mestre, Theodoro serve como pretexto para Plinio Ayrosa definir as qualidades de um bom historiador. Em verdade, Ayrosa define a atividade de fazer trabalhos históricos, pois, assim como ele mesmo, Theodoro, Taunay e Ellis Junior, nenhum deles é definido naqueles tempos somente como historiador. Suas formações são das mais díspares (engenharia e direito), e a definição que mais circula entre eles é a de "estudiosos". De modo que a competência de Theodoro é estabelecida por sua diligência, humildade e, especialmente, afinco nos estudos:

Sua vitória inconteste, a sua vitória positiva no campo das pesquisas históricas e no penumbroso ambiente vasto da linguística ameríndia, ele a atingiu graças ao próprio esforço, graças à sua tenacidade e, sobretudo, graças ao equilíbrio mental que soubera estabelecer desde os seus verdes anos de juventude.

Ao contrário de muitos historiadores contemporâneos, nunca se aventurou a conclusões históricas sugeridas por documentos e estudos fragmentados, como nunca julgou os vultos históricos à luz exclusiva de seu critério pessoal. (Idem, p. 274)

Ayrosa leva para a faculdade essa pressuposição do que deveria ser o fazer historiográfico, que vinha de seu convívio com pessoas que tinham a mesma bagagem. 0 texto para 0 Anuário da FFCL do "primeiro professor de língua tupi no mundo" falando sobre a orientação geral do curso se preocupa principalmente com as condições de pesquisa. A tarefa que arroga para a cadeira é, primeiro, a de organizar material de pesquisa para os estudos em etnografia e tupi-guarani no país. Como não havia, naquele momento, obra que conseguisse dar conta do estado da arte etnográfica no país, devia a cadeira "ocupar-se principalmente na coleta imediata do vastíssimo material de que se há de servir, tentando fixar, na caótica literatura especializada, as linhas diretoras de sua conduta" (1934-35: 142).

Ayrosa queria construir um "edifício etnográfico nacional" (Idem: 143), pois até então só encontrara obras que se confinavam a "minúsculas áreas étnicas" que "esquadrinham minúcias não raro ridículas de um dado grupo social que o acaso pôs ao alcance de suas vistas" (Idem: 141). 
Assim é que os primeiros passos da cadeira, sua função na $\mathrm{FFCL}$, seriam necessariamente os de reunir o quanto se encontre esparso pelas vastas bibliotecas nacionais e estrangeiras, capaz de servir ao seu ideal construtivo [...]. Logo após, ou concomitantemente se for possível, com a mesma largueza e tolerância, arrecadar e canalizar, para os museus brasileiros, as sobras documentais etnográficas [...] que ainda não hajam deixado se esgueirar para o estrangeiro. (Idem: 143)

Ayrosa arrola ainda, como tarefas da cadeira,

a criação de um Museu etnográfico segundo os princípios científicos modernos; a formação de uma biblioteca especializada, servida por fichários práticos e racionais; a organização de uma bibliografia minuciosa não só de etnografia brasileira como das ciências e artes conexas; a formação de um arquivo de fotografias, mapas, filmes cinematográficos, discos gramofônicos, etc.; a organização anual de uma série de conferências a serem realizadas por especialistas e membros das missões, religiosas ou não, empenhadas na catequese dos atuais indígenas do Brasil; publicação de obras inéditas, reimpressão de esgotadas e clássicas, e tradução das estrangeiras consideradas indispensáveis ao estudo de nossa etnografia; inclusão nos programas dos cursos pré-universitários, diretamente ligados à Faculdade de Filosofia, Ciências e Letras, pelo menos, de noções de antropogeografia, de pré-história e de sociologia e, finalmente, a publicação de um boletim de Etnografia que mantenha em íntimo contato os alunos com as produções modernas, servindo como vulgarizador de trabalhos acadêmicos, estimulador de estudos e de tendências mentais aproveitáveis. (1934-35: 147-148. Grifos nossos)

As atividades listadas constituem exatamente a mesma série de atividades previstas no estatuto de 1932 do IHGSP - e pelas quais, como primeiro secretário, o próprio Ayrosa era responsável:

Art. 1.0 - 0 Instituto Histórico e Geográfico de São Paulo (...) tem por finalidade promover o estudo, seu aperfeiçoamento, e a divulgação da história e da geografia precipuamente de São Paulo.

$\S$ único - Para consecução de sua finalidade, o Instituto:

a) realizará sessões ou assembleias gerais, ordinárias e extraordinárias, para os sócios; especiais para a diretoria e uma sessão magna anual;

b) manterá uma biblioteca e mapoteca;

C) manterá um arquivo e museu;

d) manterá correspondência e permuta de publicações com as sociedades congêneres, nacionais e estrangeiras;

e) manterá a publicação de uma revista;

f) promoverá excursões e festas cívicas. (RIHGSP, 1933-1934: 467. Grifos nossos) 
A preocupação com as funções de ensino-aprendizagem da cadeira vem por último, o que se reflete também no seu programa de cátedra no Anuário. Depois de estabelecidas as condições para a formação de "ambiente propício às pesquisas e aos estudos sérios" (Anuário 1934-35: 144), "restam duas palavras" a falar sobre a atuação externa da cadeira - porque todas as outras eram do que Ayrosa chama de âmbito interno -, sobre "a orientação que dará aos seus cursos acadêmicos regulamentares" (Idem: 145), que amadureceriam com 0 desenvolvimento das atividades internas. Ayrosa, assim como outros professores no Anuário, reconhece a formação precária dos alunos e, por isso, acredita que é preciso começar pelas noções de etnografia geral para só então "estudar a etnografia indígena brasileira sem necessidades de se deter em minúcias" (Idem: 146).

A parte de tupi-guarani é abordada separadamente. Ayrosa tece considerações sobre as contribuições e os limites de dois dos principais documentos com que se poderia trabalhar: os dicionários de Padre Anchieta e Montoya. De novo, a preocupação de Ayrosa é com a preparação de material adequado para os estudos de tupi-guarani. Isso para responder aos que se perguntavam se o curso ensinaria os alunos a falarem tupi: " 0 plano essencialmente cultural da nossa Faculdade jamais comportaria um curso com finalidades práticas, isto é, em que se cuidasse de ensinar a falar esta ou aquela língua, este ou aquele dialeto" (Anuário, 1934-35: 150. Grifo do autor). A finalidade da faculdade, no texto de Plinio Ayrosa, era bastante semelhante à das instituições a que pertencia: organizar o conhecimento para a continuidade de sua produção.

Ayrosa e Taunay entraram na faculdade pertencentes a um habitus que pressupunha quase exclusivamente o estudo (ou a pesquisa) e afinados com os propósitos iniciais para a universidade: a de uma instituição para a alta cultura e estudos desinteressados. Esses sujeitos são reconhecidos como "estudiosos/pesquisadores", e não como "professores". É por isso até que seus textos para os Anuários destoam tanto daqueles de seus colegas estrangeiros que mencionam a preocupação com a formação de professores como finalidade da Faculdade de Filosofia. ${ }^{11}$ Suas considerações se dirigem aos problemas de coleta, organização, seleção e produção de material para a pesquisa histórica. Pertencem a uma mesma geração, compartiIham de uma "memória comum de grupo", ${ }^{12}$ e é essa dinâmica que carregam consigo quando dentro da universidade.

É dentro desse entendimento de geração que se pode interpretar a clivagem entre os "catedráticos brasileiros tradicionais" e seus descendentes na USP. A universidade começou por reunir duas gerações diferentes, pois, apesar de convivendo no mesmo tempo e espaço, vinham de experiências distintas - a estrangeira compartilhava um passado de formação e prática institucional diferente da nacional. 
Por terem se formado no quadro das "letras históricas", no entanto, o tipo de pesquisa que produziam não encontrou validade dentro das novas regras geradas pelo campo acadêmico. Essa clivagem não passava despercebida nem pelos professores nacionais. Embora para a posteridade tenha sobrevivido a imagem de que resistiam aos professores estrangeiros, 0 próprio Ayrosa reconhece sua importância e, sobretudo, a diferença entre eles. Em depoimento para 0 Estado de São Paulo, ele discorre sobre o ensino de história e geografia na Faculdade de Filosofia logo em 1935:

Não foi por vaidade tola ou por luxo que a Faculdade contratou, na Europa, professores dos mais afamados: não foi para desdenhar dos professores que aqui vivem que chamou outros do estrangeiro. Em S. Paulo não havia ainda um centro de irradiação cultural organizado, nem um centro de formação intelectual sistematizado. Os professores estrangeiros vieram exatamente para nos ajudar a formar esse centro. Trazem-nos os mais avançados métodos de ensino e refletem, aqui, as mais altas conquistas das ciências e das letras europeias. Ora, só quem vive no ambiente culto e severo das universidades europeias pode transmitir os segredos, os detalhes, os pequeninos nadas que arcabouçam o prestigio e a eficiência das velhas universidades. Eles não vieram apenas dar aulas: vieram organizar programas, montar laboratórios, sugerir normas de ensino, corrigir falhas que nos passavam despercebidas, criar ambiente propício a novos estudos, transmitir-nos, enfim, um pouco de alma universitária. A Faculdade de Filosofia, Ciências e Letras abre as suas portas a todos os que queiram receber uma cultura sadia e moderna, livre e desinteressada, e que, com razão, lamentavam a falta, em S. Paulo, de um grande centro de estudos e pesquisas.

O governo paulista deu-nos o que pedíamos. (13/02/1935: 5. Grifos nossos)

É interessante perceber a divisão nas tarefas. A diferença entre as duas gerações era a alma universitária que os estrangeiros tinham e que ainda precisávamos criar. Havia dois regimes de produção coabitando um mesmo espaço. "Sobreviveu" aquele que deu forma à organização universitária. Essa institucionalização produziu uma terceira geração, ${ }^{13}$ cuja identidade nascia dependente desse arranjo que instituía um novo tempo do trabalho (seriado em anos) e novas formas (coletivas) de produção. Os alunos do curso, por sua vez, passaram a formar um grupo inédito, com sua própria memória compartilhada sobre o que deveria ser a produção de história e a formação de historiadores, cujo fator de agregação viria a ser a ligação com os professores estrangeiros.

\section{CONClusÃo}

bibliografia sobre a fundação da USP costuma abordar o papel do grupo do jornal 0
Estado de São Paulo, pois foi das fileiras de intelectuais, políticos e empresários que o compunham que saiu o projeto da universidade e de sua Faculdade de Filosofia. Mas, além 
disso, todos os nomes dos intelectuais brasileiros que constam das primeiras articulações para a fundação da universidade constam também na lista de sócios do IHGSP: George Dumas, Armando Sales de Oliveira, Júlio de Mesquita Filho, Theodoro Sampaio. No entanto, ao instituto é dada pouca importância nesse início de história, ainda que com três de seus sócios como professores de história.

Melhor talvez seria dizer que não é que o IHGSP esteve "presente" na fundação desse curso, e sim que o curso de história e geografia foi uma espécie de atividade paralela desses homens que se propuseram a organizar uma universidade em São Paulo. Falar em "presença" do IHGSP nas origens do curso dá a entender que este já nasceu como algo definido, independente e com identidade própria, quando o que se propõe aqui é salientar o caráter de transição dessa fase na produção historiográfica em São Paulo.

A criação do curso de geografia e história na USP não significou de imediato uma diminuição no reconhecimento profissional e do papel que o instituto exercia na escrita da história de São Paulo e, portanto, "da história nacional". 0 apelo de seu presidente junto ao interventor para a criação de cadeiras no novo curso não foi a única ação empreendida junto às autoridades. Ao contrário. Nos anos imediatamente posteriores à criação do curso, em vez de um declínio nas atividades do instituto, percebe-se a continuidade das suas boas relações com a esfera política - houve iniciativas de transferência para uma sede própria construída pela prefeitura de São Paulo em 1936 (RIHGSP, 1937, v. 32) e um convênio com o governo do estado para restauração, tradução, catalogação, encadernação e publicação de toda a documentação presente na Repartição de Estatística e no Arquivo do Estado, por meio do projeto de lei 2.800, de 28 de dezembro de 1936.

Recebendo as devidas subvenções do estado, até a publicação do volume 32 de sua revista, em 1937, o instituto publicaria seis volumes de documentação: cinco dos "documentos interessantes para a história e costumes de São Paulo" e mais um de ordens régias, o que lhe rendeu notícias elogiosas na imprensa (RIHGSP, 1937, v. 32).

O silenciamento do IHGSP nessa história acontece por uma abordagem anacrônica, que procura enxergar naqueles primórdios aquilo que já estamos acostumados a definir como "universidade", "acadêmico", "profissional" - que é a parte daqueles que "venceram", dos que se estabeleceram, em detrimento do que à época era tido como parâmetro para reconhecimento, a exemplo desses homens que circulavam nesses meios (IHGSP, Academia Paulista de Letras, Museu Paulista, IHGB etc.) e que também estiveram lá no início de tudo.

Como algo novo, a ser desenhado no seu devir, as atividades de historiador nas décadas de 1930, 1940 e até meados de 1950 ainda se encontravam no interstício entre um regime 
"antigo" e um "novo", que caminhava para definir suas regras de funcionamento, reconhecimento, legitimidade e autonomia. Saindo das práticas "amadoras", via de regra individuais e ditadas pelo ritmo do próprio indivíduo que estava produzindo, agora era preciso compartilhar as formas e os fazeres desse saber com terceiros, não mais pelo meio físico que eram os livros, mas sob novos arranjos: uma grade horária, um espaço físico, uma continuidade no tempo.

O surgimento da USP e o campo de produção de história são aqui considerados tendo em vista essas condições. Não só as práticas do fazer história se encontravam em processo de adequação às novíssimas "restrições" de tempo, espaço e sociabilização que a instituição da universidade produziu, mas a identidade de historiador profissional estavam em busca de um formato. Sendo um período de transformações para várias das atividades do campo intelectual, o curso de história e geografia que nasce em 1934 não foge desse quadro. Os modos de ser historiador e fazer história dos institutos históricos se encontram plenamente no seu nascimento.

\section{NOTAS}

1 Antonio Celso Ferreira ressalta a falta de estudos sobre a "historiografia produzida em São Paulo, principalmente a do IHGSP e a das primeiras décadas dos estudos uspianos, quando passaram por esta instituição figuras como Afonso de Taunay e Alfredo Ellis Jr., vindos da primeira agremiação" (2002: 174, nota de rodapé 2). Desde 2002, é possível verificar um incremento no número de obras. Vide, por exemplo, Um metódico à brasileira, de Anhezini (2011); Teorias raciais e interpretação histórica: o Instituto Histórico e Geográfico de São Paulo (1894-1940), de Mahl (2001); Os documentos interessantes para a história e costumes de São Paulo: subsídios para a construção de representações, de Mendes (2011); e Subsídios para a história da educação no Brasil: um estudo da eevista do Instituto Histórico e Geográfico de São Paulo, de Pereira (2013).

2 Os dados biográficos de Afonso Taunay foram retirados de Karina Anhezini (2011).

3 Os dados biográficos de Ellis Junior foram retirados do artigo de John Monteiro (1994). Conferir também 0 Capítulo 4 de Roiz (2012).

4 Os dados biográficos de Ayrosa foram retirados de Drumond (1961 e 1964).

5 Ferreira (2002) discute o projeto de história local/história nacional do IHGSP, analisando as práticas e os temas a que se dedicaram seus associados.

6 Desde 1908, Dumas havia sido indicado pelo Groupement des Universités et Grandes Écoles de France pour les relations avec l'Amérique Latine para a divulgação das obras dessa organização (Petitjean, 1996: 260). "A grande figura nesse processo de recrutamento foi o já mencionado Georges Dumas. Profundo conhecedor da realidade brasileira e amigo de membros da elite do país, Dumas tinha excelente trânsito entre as autoridades diplomáticas francesas e, ao mesmo tempo, uma inserção importante no campo intelectual e acadêmico francês. 0 fato de ser normalien e professor da Sorbonne lhe franqueava o acesso a uma rede de nomes respeitados, espalhados por diferentes instituições francesas" (Ferreira, 2005: 231).7 A criação da cadeira de etnografia e tupi-guarani não é o único movimento do IHGSP em relação às questões indígenas nesse período. No relatório de 1933, a diretoria comunica que conseguiu, com sucesso, a inclusão de sua proposta 
"para que figurasse na nova Constituição Brasileira direitos civis e políticos em benefícios dos nossos índios" (RIHGSP, 1933-1934: 418).

80 trecho é retirado da coletânea de correspondências trocadas entre Ayrosa e Archimedes Pereira Guimarães.

9 Não à toa, segundo Ferreira (2005), uma das grandes controvérsias dentro do instituto se deu em torno da filiação linguística da tribo guaianá (p. 141-149). Após a confirmação de que era dos tupis, e não dos tapuias, que os guaianás descendiam - reafirmando, pois, a dignidade dessa descendência -, "estava desobstruído, portanto, o caminho para o resgate das várias contribuiç̧ões dos indígenas tupi, de um modo geral, à civilização paulista" (p. 143). Tanto Ferreira (2002: 143) quanto Schwarcz (1993: 130) destacam a presença relevante de estudos etnogeolinguísticos e antropológicos, respectivamente, na produção do IHGSP. Essa preocupação se estendeu à primeira proposta de formação acadêmica de historiadores e geógrafos em São Paulo.

10 Que toma posse como consócio em agosto de 1936. As conexões entre as pessoas ligadas à criação do curso estão se dando por volta desse momento. Além de Armando Sales, lembremos que Júlio de Mesquita Filho, outro cabeça no projeto da USP, havia sido eleito para o quadro do IHGSP quatro meses antes da criação da universidade.

11 A função de formar professores só vai ser assumida, por um motivo bastante prático, diante da necessidade urgente de aumentar as matrículas na faculdade em 1935, pois 80\% dos alunos de 1934 não se rematricularam, e somente 123 se inscreveram para o novo ano letivo. Somando o total de alunos inscritos, a FFCL se encontrava com 12 alunos a menos do que no primeiro semestre. Para sanar essa ausência de interessados na faculdade, que estava apenas em seu segundo semestre de funcionamento, Fernando de Azevedo recorreu ao comissionamento de professores primários e secundários, que, após aprovação no exame vestibular, seriam dispensados de suas funções didáticas para fazer o curso na FFCL (Limongi, 1988: 190).

12 "Entendida enquanto testemunho de como um conjunto de homens experimentou um certo 'tempo'. Falar de geração nessa perspectiva é falar de relações entre "pessoas" de um mesmo grupo (que podem ou não ter a mesma classe de idade) e é falar também de relações entre gerações, pois há uma nítida dinâmica contrastiva nesse processo" (Gomes, 1996: 41).

13 "A noção de geração deve, portanto, transcender a manifestações 'externas', resultando de um trabalho de memória comum de grupo, que identifica sua vivência e a transmite aos seus sucessores que não a compartilharam" (Gomes, 1996: 41). Nesse caso, a "geração" de Taunay e Ayrosa não "consegue" transmitir sua vivência aos seus sucessores, pois a lógica a que pertenciam - e que também estavam eles mesmo criando, especialmente depois da década de 1940 - já era a de outra instituiç̧ão.

\section{FONTES}

Anuário da Faculdade de Filosofia, Ciências e Letras - 1934/1935. São Paulo: FFLCH/USP, 2009.

GUIMARÃES, Archimedes. Cartas de um Professor de Tupi. Plinio Marques da Silva Ayrosa. Belo Horizonte, 1982.

O Ensino de História, Geographia e Ethnographia na Universidade de S. Paulo. O Estado de São Paulo. 13/02/1935. p. 5.

Revista do Instituto Histórico e Geográfico de São Paulo. São Paulo: Gráfica Paulista, v. 30. 1931-1932. 
RIHGSP. São Paulo: Gráfica Paulista, v. 31. 1933-1934.

RIHGSP. São Paulo: Gráfica Paulista, v. 34. 1938.

RIHGSP. São Paulo: Gráfica Paulista, v. 36. dez, 1939.

RIHGSP. São Paulo: Gráfica Paulista, v. 38. jun, 1940.

TAUNAY, Afonso. Os Quatro Primeiros Lustros de Vida do Instituto. Conferência proferida na sessão de 25 de janeiro de 1914. In.: RIHGSP. São Paulo: Gráfica Paulista, v. 19. 1914.

\section{REFERÊNCIAS BIBLIOGRÁFICAS}

ANHEZINI, Karina. Um metódico à brasileira: a história da historiografia de Afonso de Taunay (1911-1939). São Paulo: Fundação Editora Unesp, 2011.

DRUMOND, Carlos. Homenagem. Professor Plinio Marques da Silva Ayrosa. Revista de História, São Paulo, n. 60,1964, p. 407- 418.

Prof. Plínio Marques da Silva Ayrosa. Revista de História, São Paulo, n. 47, 1961, p. 286-288. FERREIRA, Antônio Celso. A epopeia bandeirante: letrados, instituições, invenção histórica (1870-1940). São Paulo: Fundação Editora Unesp, 2002.FERREIRA, M. Os professores franceses e a redescoberta do Brasil. Revista Brasileira, Rio de Janeiro, ano IX, n. 43, 2005, p. 227-246.

GOMES, Ângela de Castro. História e historiadores. Rio de Janeiro: FGV, 1996.

LIMONGI, Fernando. Educadores e empresários Culturais na Construção da USP. Dissertação (mestrado) Instituto de Filosofia e Ciências Humana/Universidade Estadual de Campinas, Campinas, 1988.

MAHL, Marcelo. Teorias raciais e interpretação histórica: o Instituto Histórico e Geográfico de São Paulo (1894-1940). Dissertação (mestrado) - Programa de Pós-Graduação em História/Universidade Estadual Paulista, São Paulo, 2001.

MENDES, André Oliva Teixeira. Os documentos interessantes para a história e costumes de São Paulo: subsídios para a construção de representações. Dissertação (mestrado) - Programa de Pós-Graduação em História Social/Universidade de São Paulo, 2011.

MONTEIRO, John. Caçando com gato: raça, mestiçagem e identidade paulista na obra de Alfredo Ellis Jr. Novos Estudos Cebrap, São Paulo, v. 38, 1994. p. 79-88.

PEREIRA, Maria Aparecida. Subsídios para a história da educação no Brasil: um estudo da revista do Instituto Histórico e Geográfico de São Paulo. Tese (doutorado) - Programa de Pós-Graduação em Educação/Universidade Federal de São Carlos, São Carlos, 2013.

PETITJEAN, Patrick. As missões universitárias francesas na criação da Universidade de São Paulo (1934-1940). In: HAMBURGUER, Amélia et al. (Orgs). As ciências nas relações Brasil-França (1850-1950). São Paulo: Edusp/ Fapesp, 1996.

ROIZ, D. Os caminhos (da escrita) da história e os descaminhos de seu ensino. Curitiba: Appris, 2012. 